Amaltea. Revista de mitocrítica

ISSN-e: 1989-1709

http://dx.doi.org/10.5209/amal.66691

\title{
Alternativas para el fin del mundo: mito, destino trágico y ciencia ficción
}

\author{
Luis Alberto Pérez-Amezcua ${ }^{1}$; Ethel Junco²
}

Recibido: 2/12/2019/Aceptado: 18/5/2020

Resumen. Proponemos una lectura de Terminator: Dark Fate, la más reciente entrega de una de las sagas cinematográficas más influyentes de la ciencia ficción contemporánea, y la contrastamos con el sentido del destino trágico clásico de Las troyanas, de Eurípides. A partir de la configuración del mitema de la madre protectora en las dos protagonistas (Hécuba / Sarah Connor), destacamos los mitemas que funcionan como nexos entre ambas. Respetando las propiedades de cada género, observamos que la figura de la mujer-madre tiene una posición activa ante el destino con la cual define su tipo heroico y la suerte de su comunidad. Concluimos afirmando que la eficacia del mitema que sostiene el texto fílmico se asienta más en el paradigma mítico que en el científico.

Palabras clave: Terminator; Eurípides; mitocrítica; ciencia ficción; mitología; cultura de masas; literatura; teatro antiguo.

\section{[en] Alternatives for the end of the world: myth, tragic destiny and science fiction}

\begin{abstract}
We propose a reading of Terminator: Dark Fate, the most recent installment of one of the most influential film sagas of contemporary science fiction, and we contrast it with the sense of the classic tragic destiny of The Trojans, by Euripides. From the configuration of the mytheme of the protective mother in the two protagonists (Hecuba / Sarah Connor), we stand out the mythemes that function as links between both of them. Respecting the properties of each genre, we observe that the woman-mother figure has an active position facing destiny with which she defines her heroic type and the fate of her community. We conclude stating that the mytheme's efficacy that sustains the filmic text it is based more on the mythical paradigm than on the scientific one.
\end{abstract}

Keywords: Terminator; Euripides; myth criticism; science fiction; mythology; mass culture; literature; ancient theater.

Sumario. 1. Introducción. 2. Textos en relación. 2.1. Las troyanas. 2.2. Terminator: Dark Fate. 3. Detección y tratamiento de los mitemas. 4. Consideraciones sobre mito y ciencia ficción. 5. Reflexiones finales. Obras citadas.

Cómo citar: Pérez-Amezcua, L. A. y Junco, E. Alternativas para el fin del mundo: mito, destino trágico y ciencia ficción. Amaltea. Revista de mitocrítica, 12, 2020,37-45.

\section{Introducción}

En 1984, la industria cinematográfica nos ofreció The Terminator (James Cameron), una amalgama de acción, cibernética y heroísmo para pensar, una vez más, el mundo en riesgo; el impacto internacional la convirtió en una saga con sucesivas propuestas de nivel desigual; en 2019 se estrenó otra secuela, Terminator: Destino oculto (Terminator: Dark Fate, Tim Miller), con dos de sus actores principales originarios, Linda Hamilton y Arnold Schwarzenegger, elección que sutilmente retoma el problema inicial.

Para acercarnos a una mejor comprensión de este relato de ciencia ficción, cuya creación de mundos detallados es crucial (Jenkins 116), proponemos analizarlo a la luz de los elementos míticos fundamentales que estructuran su argumento y ofrecen una narrativa conjugada con las visiones de época; no quisiéramos referirnos a lo obvio, dentro de un mercado en el que es preciso potenciar las nociones de tolerancia, integración racial, anulación de fronteras y diversidad de género, sino al dinamismo que conjuga todas las piezas de superficie. Por ende, y bajo el enfoque

Universidad de Guadalajara (México) perez.amezcua@academicos.udg.mx https://orcid.org/0000-0002-8336-7128

Universidad Panamericana (México) ejunco@up.edu.mx

https://orcid.org/0000-0002-3369-0576 
hermenéutico de la mitocrítica, destacaremos los mitemas primordiales que funcionan como llaves de apertura y consumación del destino.

Seguimos el enfoque de Gilbert Durand para correlacionar la obra artística con la configuración histórica desde la matriz mitocrítica; sostenemos el caudal simbólico de la narración en su soporte mítico interno, que hace inseparables representación y sentido. Observamos nuestra materia de análisis en busca de los mitemas que la vertebran -“es decir, las más pequeñas unidades semánticas señaladas por redundancias" (Durand, Mitos 163)- y que se jerarquizan con el fin de ofrecer un sentido fundamental. Si bien el mensaje resultante no necesariamente responde a la matriz, la elección de los mitemas guarda una relación intencional con el significado (Durand, De la mitocrítica 344-354).

Desglosaremos, entonces, la materia argumental de la película y la remontaremos a un paradigma de origen, cuyo funcionamiento activa la relación hipotexto-hipertexto. Como hipotexto proponemos la lectura en relación con Eurípides, particularmente en las tragedias que tienen por protagonista a la reina de Troya: Hécuba y Las troyanas. Con base en el perfil configurado en la primera, nos centraremos solo en la segunda, para destacar el tipo femenino de madre que ampara, sufre y ejerce venganza, bajo el marco de la guerra total. Como hipertexto, leeremos al personaje de Sarah Connor en Terminator: Destino oculto.

Si bien aceptamos la acepción de la ciencia ficción como la propuesta narrativa que "no podría surgir en el mundo tal como lo conocemos", no deja de ser "una historia construida alrededor de seres humanos" (Shippey 6) 3 , lo que conduce a un problema y a un tratamiento último que se da en la lógica de las decisiones personales. En ambos casos y con las propiedades de cada género, tragedia y ciencia ficción, intentaremos aunar el modelo femenino con la noción de destino, que tiene preeminencia en el título elegido para la película; dejamos de lado el punto de la traducción al español y su acepción para dark, ya que, en nuestro interés, es equivalente que el destino sea "oscuro" u "oculto", pues la intervención humana (materna) se cumplirá igualmente.

La ciencia ficción se ocupa, generalmente, de imaginar experiencias en el futuro, contando con el elemento predictivo del saber racional y fantaseando acerca de sus efectos. Lo conjetural se expande para proponer la construcción de otro mundo plausible dentro del mundo real conocido, un mundo que es "«otro» pero tan «verdadero» como el real" (Volli $121)^{4}$, donde lo extraordinario se vuelve natural y lo verosímil se percibe a la luz de miedos atávicos. Se busca en los confines del futuro el secreto del origen; en ambos puntos se trata de ingresar en territorios fuera del límite.

La predicción sobre hipótesis científicas, como materia argumental, se vincula en el horizonte mítico con la sabiduría oracular, aquella penetración en el secreto del destino que desvela a dioses, héroes y simples mortales. Pitonisas, augures, profetas, magos y demás partícipes del saber oculto están investidos de verdadero poder, superior al de filósofos y gobernantes. Los que portan un dato sobre el destino, y con su presciencia modifican, son los genuinos participantes del orden del cosmos.

El destino es objeto de reverencia en el mito y en la ciencia ficción; desde la materia argumental, ambas especies literarias están consagradas a él, definiéndolo, acotándolo, enfrentándolo. Esta "urgencia" en atender el problema del destino se verifica en la articulación de tres instancias que, según nuestra consideración, son compartidas por ambas especies:

1. La interpretación escatológica de los sucesos, que pone el asunto en una perspectiva integral, intentando abarcar desde el inicio del cosmos hasta su fin; en ambas especies se da una cercana convivencia con seres extraordinarios, divinidades, extraterrestres u organismos cibernéticos que tienen acceso a los extremos del tiempo.

2. El tratamiento de fuerzas y eventos que desestabilizan la vida común, conducen a catástrofes naturales o morales y acarrean planteamientos profundos acerca del sentido de la existencia.

3. La búsqueda de soluciones a los grandes problemas y la superación de los peligros por medio del ingenio y el valor humanos, de la interacción con capacidades superiores o poderes sobrenaturales; la supervivencia en riesgo -ya cósmica, ya psicológica- es protegida en términos de una guerra total con recursos extremos.

La figura de la mujer-madre, que se privilegia en ambos textos, tiene una posición activa ante el destino con la cual define su tipo heroico y la suerte de su comunidad.

\section{Textos en relación}

\subsection{Las troyanas}

En el contexto de la aristocracia guerrera de cuño homérico, así como en la organización de la ciudad democrática, el varón es centro: héroe en el combate y orador en la asamblea, respectivamente. La mujer es generadora de hombres dignos para la guerra y para el estado (Cantarella 91).

Grecia reformula la tradición mítica como ninguna otra cultura (Kirk 259) y ofrece en el paradigma de Troya un principio a partir del cual queda marcada la identidad de nuestra civilización: Occidente nace con la lógica de la

\footnotetext{
"Science Fiction is that class of prose narrative treating of a situation that could not arise in the world we know" y líneas abajo: "A science fiction story is a story built around human beings" (la traducción es nuestra).

4 "«other», but just as «true» as the real one" (nuestra traducción).
} 
guerra. La materia épica ha brindado el sustrato normal de las obras literarias hasta nuestros días (De Romilly, $L a$ tragedia 22). Así, la conquista, la gloria, el dominio serán las metas del hombre; el héroe se impone, carga riquezas y vuelve a su patria. Detrás, queda el territorio expoliado y las víctimas menos significativas, los viejos, las mujeres y los niños. En las tragedias mencionadas, Eurípides acentúa el efecto desmoralizador de la guerra (Hajdu 19).

Las troyanas, obra que se ocupa de Hécuba, Andrómaca, Casandra y las nobles vencidas, se ordena solo alrededor de Hécuba (Grube 272; Conacher 138): la reina, viuda y madre que ha sido despojada de su prolífica descendencia $\mathrm{y}$, en especial, del heredero designado para salvar la ciudad, Héctor, quien ha perecido bajo la ira de Aquiles. Si su intervención en el mundo de la guerra había sido transversal, las circunstancias la obligan a convertirse en protagonista; al hacerlo, debe adoptar estrategias de los agresores aunque revierta su finalidad. La resonancia de Troya, condicionando un futuro oscuro (un dark fate) se activa en la memoria colectiva ante cada conflicto mundial; así lo hizo Eurípides con la historia de Atenas (Croally 57) y lo hacen las narrativas actuales. Troya remueve la duda perenne: aunque las motivaciones del conflicto parezcan claras y justificables al inicio, sus consecuencias las cuestionan; victoriosos y vencidos son categorías ambiguas y a veces intercambiables.

Las troyanas se abre con el escenario de la ciudad caída, el incendio inminente como fondo, y el reparto de bienes y mujeres entre los guerreros griegos, mientras preparan estos sus naves para partir. Sin embargo, aunque todo anticipa una pieza sin sorpresas argumentales, donde solo se expongan los niveles del sufrimiento, otra forma de la guerra se yergue a partir de la antigua mujer, valiente pero no independiente (Lefkowitz 139) que será la próxima heroína. Como la guerra está aún activa en los posibles vengadores, Hécuba intentará vanamente defender a Astianacte, hijo de Héctor, único varón vivo de la estirpe, quien representa el peligro del regreso y del resarcimiento: "diciendo que no hay que dejar crecer al hijo de un hombre excelente" (v. 723)5.

La obra apela a un manejo del tiempo que enlaza con el recurso flexible de la ciencia ficción: Poseidón, quien observa el desastre humano y decide retirarse de Troya, sabe que los griegos pagarán sus errores; el dios ve el castigo final y lo anuncia:

Es necio el mortal que destruye ciudades; si además deja en soledad templos y tumbas -santuarios de los muertos- prepara su propia destrucción para después ${ }^{6}$.

El dios maneja el fin de la historia y sabe que los actos pasados tendrán su desagravio; pero no lo saben los mortales, que intentarán una comprensión propia. Frente al horizonte dejado por la guerra, los dioses consienten el abatimiento de uno y otro bando (Vidal Naquet 37) y luego se distancian: "El amor de los dioses por Troya se ha ido" . Queda para los humanos, para las mujeres en su función de madres en este caso, luchar por la justicia o por la supervivencia.

Aunque en el plano divino la hamartía será equilibrada, el problema trágico es el origen del sufrimiento de los inocentes, que permanece inexplicable y funda el pesimismo del presente: "una muchedumbre de hijos a las puertas lloran colgados del cuello de sus madres". A los protagonistas no les satisface la certidumbre de los dioses por encima del tiempo; el pasado determina un error para el futuro (Easterling 174) y dejarlo impune implica ser cómplice, acentuar la injusticia, causar más destrucción. La luz de supervivencia para Troya está representada por las mujeres de los héroes y por el hijo de Héctor, cautivas de guerra y niño indefenso: “¡Mirad, aquí, tristes esposas de los troyanos, a Astianacte muerto". Mas no hay compasión para nadie (García Gual 281): las cautivas son entregadas a los guerreros, arrastradas a las naves y enviadas hacia destinos de sometimiento; el nieto de Hécuba es arrojado desde los muros de la ciudad y luego expuesto sobre el escudo de su padre: "Hijo, oh hijo de mi pobre hijo, de tu vida privadas nos vemos injustamente tu madre y yo"10.

Casandra, quien advierte las desgracias en el destino de Agamenón, no tiene ningún eco (Scodel 148). En ese horror, no obstante, se inicia la reconstrucción, representada por el enterramiento de Astianacte; el rito fúnebre de la víctima inmolada es cierre de la guerra y reinicio de la posibilidad de la paz: "Marchad, enterrad el cadáver en su desdichada tumba" ". Con el sufrimiento intacto, Hécuba como madre de todos es la que comprende la necesidad de esa entrega y, después del acto de piedad, hace suyos simbólicamente a cuantos huérfanos ha dejado la guerra: "Pero soy yo, una anciana sin ciudad y sin hijos, quien entierro tu triste cadáver de joven; no tú a mí" 12 .

Del punto de fracaso inicial y de una lógica agresiva se pasa a una lección pacificadora regida por el sentimiento materno: si la guerra empezó por voluntad masculina, lo femenino intervino para reordenar el destino. Aunque la mirada final sea pesimista (Meltzer 103) y la guerra no traiga progreso sino barbarización (Vela Tejada 129): “¡Oh, griegos, inventores de suplicios bárbaros!"13, son las madres despojadas de sus hijos las que quedan para sostener una idea de identidad y, acaso, de patria.

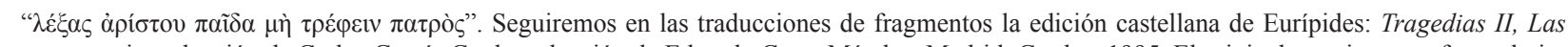
troyanas, introducción de Carlos García Gual, traducción de Eduardo Costa Méndez, Madrid: Gredos, 1995. El original en griego se ofrece al pie.

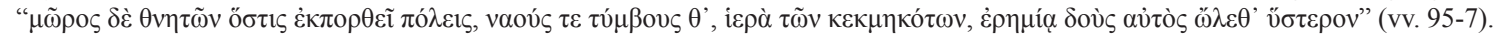




\subsection{Terminator: Dark Fate}

Cumpliendo con los requisitos de la ciencia ficción, la saga Terminator ofrece una visión apocalíptica de la historia, un mundo posible de acuerdo con características establecidas en el presente (Eco 1257), con constantes intervenciones magníficas y cruces de época que procuran interrumpir la amenaza del desastre y ofrecer un futuro; con Tim Miller como director y James Cameron como productor, en 2019 se vuelve a corporeizar el gran temor humano engendrador de mitos, es decir, la vieja pero nada obsoleta historia del hijo del hombre rebelado contra su creador.

La versión de 2019 retoma la trama de Terminator 2: Judgement Day (James Cameron, 1991) sin considerar las dos secuelas intermedias, Terminator Salvation (Joseph McGinty Nichol, 2009) y Terminator: Génesis (Alan Taylor, 2015). El eje gira en torno a los esfuerzos para salvar a Daniela "Dani” Ramos del último modelo de Terminator, cuya misión es aniquilarla; sus protectoras serán Grace, una humana mejorada tecnológicamente, y la afianzada Sarah Connor, quien dedicó su vida a la destrucción de Terminators luego de que el T-800 asesinara a su hijo. Como figura contraria, se integra un personaje maligno en extremo, antagonista inmodificable, el Rev-9, que llega del futuro por orden de un sistema inteligente denominado Legión.

El dúo que enfrenta voluntades de la inteligencia artificial con la resistencia humana se complementa en esta versión con el viejo Terminator, inconfundible alter ego de Schwarzenegger; aquel que representó el ciborg por excelencia - una combinación de "máquina militarizada y humano hipermasculino" (Schmeink 35)-, que ha adquirido un cierto nivel de consciencia; por ello, ahora colaborará para evitar la destrucción de la humanidad: "Cuando mi misión fue completada, no hubo más órdenes. Así que por veinte años me mantuve aprendiendo cómo convertirme en más humano"14. A partir de allí, la confrontación entre máquinas inteligentes -aunque profundamente irracionales en sus causas- y humanos fortalecidos por un ideal, arma la trama. Dentro de un espacio pseudocientífico se insertan problemas concretos que no necesitan ser explicados porque pertenecen al mundo real (Pavel 32): género, migración, pobreza, discriminación.

La ficción se potencia en el cruce de líneas temporales, en los viajes posibles entre ellas y en la capacidad de la ciencia de modificar la naturaleza humana: Grace, la ciborg protectora, aparece en el presente enviada desde el futuro por la misma Dani, a quien debe salvar, pero que, en otra línea temporal, fue su salvadora y líder de la resistencia; vuelve para devolverle el favor, pues ella la ha salvado en el tiempo distópico y así, circularmente, para salvarse a sí misma junto con toda la humanidad. Es un personaje rudo por su historia de abandono en un futuro cruel y por su entrenamiento militar, pero claramente empático e indisociable de su cometido, el cual se identifica con su vida. Cumplida la misión, el cierre de la película restaura el pasado en el nuevo presente.

La idea de que alguien que vive en el futuro quiere corregir los acontecimientos, habitual en la ciencia ficción, cuestiona la noción de destino, propia del mito. La ciencia es por definición correctiva y lineal, pero el mito es revelador y circular. Aquí se resolverá míticamente un dilema planteado por la ciencia ficción.

\section{Detección y tratamiento de los mitemas}

Los mitemas de una historia base o hipotexto (Genette 13) son transformados y direccionados en cada nueva interpretación. Como unidades menores de significado preparan el mensaje que quedará de modo mixto, más o menos explícito, de acuerdo con el nivel de resonancias del lector/espectador. Presentamos cuatro mitemas para su análisis, encabezados por el principal, el de la madre que, a causa de la guerra, debe intervenir en el destino a través del héroe.

La saga Terminator potencia la figura femenina. De un modo semejante, Eurípides incorpora en su discurso trágico la voz de la mujer dentro de un marco histórico en que lo femenino estaba recluido al hogar y marginado de la vida política (García Gual 282). El trágico, ubicado entre la época clásica y el helenismo, es testigo de un cambio de paradigmas, lo que ofrece semejanzas con la actualidad postmoderna. Eurípides describe la pasión de la guerra que lleva fuera de todo límite moral (De Romilly, Grecia 16) y la convierte en motivo de reflexión para condenarla: "Si dices algo que enoje al ejército, tu hijo no tendrá tumba ni funeral"15.

Hécuba y Sarah Connor representan a la mujer definida como madre, que ejerce la protección de todos, hijos y mundo. Ambas han atravesado el horror de ver morir a sus hijos por causa de la irracionalidad de una guerra que no produjeron y que se interpuso en sus vidas; ambas son madres de líderes en cuyo poder está la continuidad de un tipo de vida. Han tratado de evitar que los antagonistas se apoderen de su mundo: Hécuba resiste, aun después del final, enfrentando a Agamenón y a Ulises en el reparto de cautivas, para conseguir una mínima mejoría en la vida de los vencidos; Sarah Connor, en la precuela de la actual película, evitó la guerra entre máquinas y humanos generada por el sistema inteligente Skynet, así como en esta evita la intención aniquiladora de Legión.

Ambas tienen un centro de sus cuidados; para Hécuba, que ha perdido a Héctor, será el pequeño Astianacte, por quien suplica vanamente y a quien debe enterrar sobre el escudo de su padre: "Depositad en tierra el bien torneado

\footnotetext{
14 "When my mission was completed, there were no further orders. So, for twenty years, I kept learning how to become more human" (la traducción de los fragmentos de la película es nuestra).

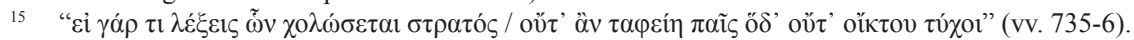




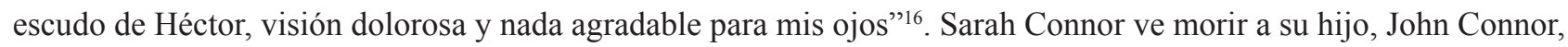
a manos del Terminator T-800 y se determina a ordenar su vida a la venganza, hasta que reaparece un nuevo motivo de esperanza, Dani, prolongación de su hijo, a quien defenderá y acogerá al final, cuando no quede nadie más.

Ubicamos un mitema inicial y desencadenante del conflicto, el de la guerra total, que deriva en dos: por un lado, el destino en su consideración negativa (concatenación de males) y por otro, el nacimiento del héroe que deberá enfrentarlo (que incluye a los desterrados de la tierra); entre ambos, aparece el mitema principal, el de la madre protectora, tierra que sostiene, nutre, proyecta y acoge en su seno:

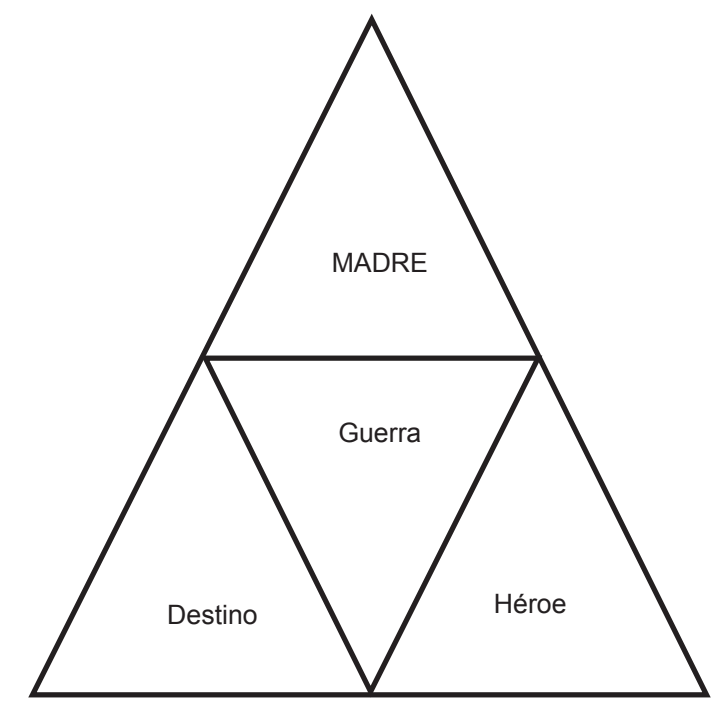

El mitema de la guerra total marca fin y principio: la gran guerra entre dioses y titanes indica la experiencia constante de contrarios en pugna para dar a luz un nuevo orden (Jaeger 121); alude, además, al inicio de los tiempos y a la noción de pérdida del estado de inocencia; un error humano, asociado con la fascinación del propio yo, conduce a la caída.

La guerra de Troya es consecuencia de la autofascinación por vanidad de la belleza y Terminator de la autofascinación por la racionalidad científica; en el primer caso, el mito ofrece como justificación a Helena, desde el misterio de lo divino, o a Agamenón, desde la lógica mezquina del poder; en el segundo, el progreso desorientado de la ciencia deriva en autonomía de los fines. La inteligencia artificial actúa de espejo para aumentar la imagen del hombre, que siempre rechaza sus límites. El desorden de la voluntad impone la absolutización de un medio relativo y convierte la violencia en instrumento de consecución. Como en Troya, la guerra es total y conlleva al fin del mundo tal como se concebía.

En el paradigma mítico, la madre ayuda a ganar la guerra. Gea revela a los dioses nuevos el secreto para acceder al poder; solo por su intervención obtienen el triunfo (Kerényi 31).

El mitema del destino indica la anterioridad al mundo, a los dioses y a los hombres. El destino -Ker, Moiras, Parcas, incluso Erinias- puede estar representado como fuerza impersonal e inescrutable o como dios personal, pero siempre en calidad de interventor y no necesariamente asociado con la retribución justa por las acciones; un estado de alternancia entre esperanza y resignación pone en duda la justicia divina tanto como la arbitrariedad del destino (Versnel 162). Pero, al contrario, en nuestras obras se produce una intervención humana, no sobrenatural, para reescribir lo prescripto: Hécuba, ante la retirada de los dioses, queda como única fuerza en pie para representar a Troya. Franqueada por los enemigos, elige la asunción de un dolor supremo para convertirlo en defensa de la sepultura de los suyos; Hécuba está sola para portar la memoria con dignidad: "A mí no me queda ni la esperanza, cosa que tienen todos los mortales"17.

En el caso de Sarah Connor, su vida es resistencia al destino que ordenó la muerte del salvador, y su reinvención como heroína se cumple al asumir la maternidad de la próxima salvadora de la humanidad: "Algunas veces las mamis y los papis deben tener conversaciones de adultos" 18 , dirá Sarah luego del reclamo por haber dejado encerrada a Dani para discutir con Grace. No obstante, Sarah y Dani son presencias tutelares, que toman el destino recibido desde afuera hasta donde les es dado frenar las consecuencias de la caída y manifiestan "un modo de ser" (Lesky 146) preservando los espacios de vida. La Dani del futuro, al encontrar a la Grace niña, la rescatará de una pandilla de desesperados por el apocalipsis, generando su maternidad y reclutando soldados al mismo tiempo: "Me salvaste. Y me criaste, y me enseñaste a tener esperanza, como salvaste y enseñaste a los otros" ${ }^{\prime 19}$, contará la Grace adulta a la Dani del pasado.

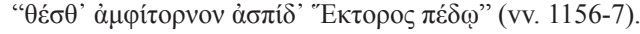

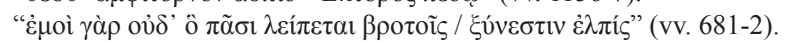

"Sometimes mommies and daddies have to have grown-up discussions".

"You saved me. And you raised me, and you taught me to hope, like you saved and taught the others".
} 
El mitema del héroe retoma la imagen del salvador elegido entre los abandonados de la tierra, el hijo expósito de los mitos, el simple de los cuentos maravillosos; el último en el que repararían los poderes del mundo es quien guarda la inocencia necesaria para la redención. Lo define haber enfrentado las limitaciones personales e históricas y haber alcanzado una "forma humana válida" (Campbell 19). Cuando vence al monstruo, como Teseo al Minotauro, vuelve sobre los suyos como símbolo de civilización. El héroe ofrece su virtud; su hazaña está en entregarla públicamente por medio de una acción ejemplar; la muerte física consolida su mérito y le otorga el honor de su comunidad (Reale 209).

De un lado, el Astianacte sin culpa que arrojan de las murallas de la ciudad que debió defender y cuyo único acto es ser sepultado sobre el escudo de su padre, símil de cuna y de féretro; de otro, John Connor o Dani Ramos, hijos de alguien corriente, ignorantes de su importancia, dedicados a vivir naturalmente. Héroes comunes que nacen para desaparecer y, sin embargo, dejan huella de restauración a su paso porque las fuerzas del destino "oculto" saben que serán los encargados de contrarrestarlo. John Connor no tendrá oportunidad y su papel será retomado por la joven mexicana, en el nuevo presente, hija y hermana cariñosa y trabajadora comprometida y, del otro lado del tiempo, líder de la resistencia y protectora de desamparados, figura materna ella misma, guerrera activa. La simplicidad del héroe se extiende a su entorno de pertenencia, considerado insignificante por los dueños del discurso. Los migrantes también son los "sin madre", los sin tierra protectora, los peregrinos en busca de destino.

En ese escenario de composición triple se presenta con toda fuerza el mitema de la madre defensora, que consideramos está representado en dos fases complementarias. Por un lado, Gea, diosa generadora de vida, madre de todos los dioses, principio cosmogónico desde donde nacen y adonde vuelven todos los seres (Jünger 2006). Por otro, Deméter, que en ocasiones es la identificación antropológica de Gea, pero añade atributos. Gea es dominadora del destino y sus oráculos considerados "más antiguos y seguros" que los de Apolo (Grimal 212), como si su fecundidad trascendiera el legado material del ser al conocimiento de los sucesos de esa misma vida. De Gea y de su maternidad prolífica y monstruosa se deriva el carácter salvaje en la protección de la descendencia (Grimal 98), un caudal irrefrenable de energía capaz de confrontar más allá de la racionalidad. De Deméter, como incremento, se debe tener en consideración su maternidad única y la exclusiva dedicación a Perséfone, hija que debe ser entregada en la plenitud de su inocencia al inframundo de Hades. Ambas son identificadas como "las Diosas", unidad que se reclama en la búsqueda de una y en el llamado doliente de la otra para ser rescatada. El peregrinaje que inicia la madre en busca de su hija, la renuncia al Olimpo, su transformación en vieja, el vagabundeo por el mundo, su función de nodriza entre los mortales (Grimal 132) dan forma a los relatos en cuestión.

La función materna está definida por el principio de que la vida que sustenta tiene sentido absoluto; las acciones de la madre deben sostener el equilibrio entre paz y vida, guerra y muerte (Vernant 88), en función de la supervivencia de los descendientes. El paradigma materno se fortalece ante la desaparición del sucesor; si no es posible recuperar al hijo, y más aún, cuando el hijo ha sido asesinado sin razón, se redefine la condición materna: la maternidad no es una experiencia biológica acotada, sino un estado expansivo del ser.

Los mitemas correlacionan a los personajes de Hécuba y Sarah Connor en cuatro niveles:

1. Mitema de la madre protectora: inversión del dolor en solidaridad. La fragilidad de lo femenino convertida por las circunstancias en fortaleza vencedora.

2. Mitema del destino trágico: inmanentismo de causas y consecuencias; el mal y el bien del corazón humano como principios únicos ante un posible fin.

3. Mitema del héroe civilizador: superación de la barbarie en la relación interpersonal. Aptitud para el sacrificio capaz de producir un cambio comunitario.

4. Mitema de la guerra total: implicación en cosmovisiones distanciadas de la esperanza, o de una perspectiva providencialista de la historia, y centradas apenas en la supervivencia en el presente.

La imagen femenina se configura como ideal. Ninguna de estas mujeres es real, como tampoco lo son los hombres en las representaciones heroicas; si se trata de invertir el orden de un destino, principalmente apoyado en decisiones masculinas, el nuevo modelo de cohesión debe encarnarlo una mujer superior (Becker 216).

Los mitemas laterales convergen en torno al mitema central: la madre media en la guerra en defensa del héroe interviniendo en el destino. Previo a la instauración de un orden masculino, anterior a Zeus y a la ley que garantiza, el destino es femenino y dependiente de una trinidad en la tradición griega: son tres las diosas que comparten la función de Madre del Mundo (Tetis, Noche y Tierra) y tres las diosas que se distribuyen el control del Destino (Cloto, Láquesis y Átropos) (Kerényi 37-38). Mito y ciencia ficción se enlazan en el destino trágico, pasando necesariamente por la figura de la madre que reinstaura un cosmos en el que el paradigma no pasa únicamente por la vía del varón guerrero.

\section{Consideraciones sobre mito y ciencia ficción}

Respetando las propiedades de cada especie literaria, nos interesa destacar las afinidades en los modelos elegidos. Las condiciones requeridas para lograr la salvación del futuro implican cambiar la noción de destino al compensar la tragedia. Ambas protagonistas intervienen produciendo ese cambio: si el destino implica partir de la determinación 
negativa, como consciencia de límite y de sufrimiento, sendas mujeres imprimen el mismo giro. El cuadro siguiente ofrece una relación:

\begin{tabular}{|c|c|c|}
\hline & Hécuba & Sarah Connor \\
\hline Destino & La voluntad de los dioses & $\begin{array}{l}\text { La voluntad de una inteligencia } \\
\text { artificial }\end{array}$ \\
\hline Designio & La guerra de Troya & La guerra máquinas-humanos \\
\hline Constante cultural & $\begin{array}{l}\text { Destructividad masculina; } \\
\text { pasividad femenina }\end{array}$ & Femenino-masculino en interacción \\
\hline Cambio impreso & Reactivación de la decisión femenina & Voluntad femenina definitoria \\
\hline Acción femenina & De la resignación a la superación & Reacción ante la determinación \\
\hline Virtud femenina & Fuerza, tesón, compasión & Fuerza, tesón, compasión \\
\hline Diferencia femenina & $\begin{array}{l}\text { Evolución de la interioridad: de Erinia } \\
\text { a Euménide }\end{array}$ & Alianza en afectos extrafamiliares \\
\hline Intervención en el destino & $\begin{array}{l}\text { La madre corrige la voluntad divina y } \\
\text { suspende el curso de la adversidad }\end{array}$ & $\begin{array}{l}\text { La madre rectifica la voluntad de una } \\
\text { inteligencia artificial y abate la fuerza } \\
\text { de otra }\end{array}$ \\
\hline Intervención en la historia & $\begin{array}{l}\text { Helenismo, sentimiento de azar e } \\
\text { incertidumbre }\end{array}$ & $\begin{array}{l}\text { Posmodernidad, cuestionamiento por } \\
\text { el sinsentido de la historia }\end{array}$ \\
\hline Perspectiva & $\begin{array}{l}\text { Continuidad de la historia por } \\
\text { mediación del carácter materno }\end{array}$ & $\begin{array}{l}\text { Continuidad de la historia por } \\
\text { mediación del carácter materno }\end{array}$ \\
\hline
\end{tabular}

Además de las afinidades, destacamos una especificidad diferencial que aporta la película. En medio del desvanecimiento de límites que propende la corriente posthumanista, según la cual no son significativos los contornos entre humano y no humano, hombre y mujer, mente y cuerpo, primitivo y civilizado (Haraway 131), la ciencia ficción pronuncia una exhortación ética. Así como el desencadenante del conflicto es el desorden de la inteligencia artificial (IA), el cierre del conflicto muestra la posibilidad de conversión: la IA puede hacer una ida y vuelta: del bien de su intención al mal de su acción autónoma, al bien de su toma de consciencia, lo que expone una perspectiva esperanzada. Terminator 2: Judgment Day ya había mostrado la empatía entre el robot y el niño, anticipando que las máquinas podrían ser capaces de sentir afecto; en Terminator: Dark Fate el personaje que interpreta Schwarzenegger ha evolucionado hacia sentimientos humanos: el robot ama. La adopción de una familia y el cuidado del hijo de su pareja (otro signo de futuro y de destino) lo han llevado a reflexionar sobre sus actos y a ser capaz de arrepentirse -racionalmente, desde luego- por la misión de asesino que lo trajo a este mundo. Por eso, como en todo proceso purificatorio, tendrá un camino de renuncia, padecimiento y muerte. El robot muere a la vida antigua y renace simbólicamente cuando decide ser otro protector de John, a quien dedica su sacrificio. Así rompe su destino esclavo de una inteligencia artificial maligna (Baudrillard 120) y su sistema operativo se apaga siendo libre. Es probable que el punto culminante de la película sea la mirada de recíproca comprensión entre el Terminator semidestruido y Sarah Connor, punto donde se sintetizan arrepentimiento, ofrenda y perdón.

Puede que los escenarios externos de Hécuba y de Sara Connor no hayan cambiado esencialmente y que los peligros que atacaron estén prestos a emerger, pero la interioridad de ambas se ha modificado. Han tomado su experiencia trágica y la han sacado del horror del pasado, como punto clausurado, para depurarla hacia el futuro; en su tránsito de muerte a vida ninguna es igual a sí misma porque la purificación del dolor las ha clarificado; ambas asumen la misión asignada a sus hijos muertos en una heroicidad contagiada por el acto de dignificarlos.

Tragedia y ciencia ficción se comportan igualmente como textos ficticios que describen un estado de cosas que, aunque no correspondan a la experiencia cotidiana y rutinaria, plantean su posibilidad de existencia; en este "estado de cosas" específico, aúnan con el mito una propuesta de lo femenino que se compenetra en los designios inescrutables del destino y opera en ellos con sus capacidades propias. Los finales condicionan el futuro a tal intervención, conveniente para un mundo disgregado. El discurso del arte ofrece una afirmación similar a la del discurso sagrado (Durand, Ciencia 100-101) al orientar inquietudes colectivas homogéneas, aunque pertenecientes a muy distantes momentos históricos.

\section{Reflexiones finales}

La red de mitemas detectados permite visualizar un tejido lógico. Desde raíces míticas universalizables se ofrece una perspectiva hermenéutica de época; el acceso mitocrítico propone una respuesta sociocultural, cumpliéndose el paso que Durand señala de la mitocrítica al mitoanálisis. La elección de un tópico mítico en clave científica permite pensar diacrónicamente problemas y necesidades interpersonales.

Bajo la trama de los textos correlacionados, encontramos: 
1. Una rehabilitación del sentido de la justicia que, motivada por la pérdida del descendiente, evoluciona desde la venganza y se convierte en defensa del conjunto social; como se ha perdido al salvador del mundo, la madre debe ser mediación para seguir protegiendo al mundo.

2. Una purificación por el dolor que se resignifica en compasión por los marginados de la tierra y en posible fundamentación de un nuevo tejido social.

3. La refundación de vínculos sobre el eje familiar, superador de relaciones de sangre, con centro en la madre como conducto simbólico.

4. La intervención de la madre en el destino que sobrevuela paradójicamente la invariabilidad mítica de la determinación y el desconocimiento de la trama escatológica; la capacidad "sobrenatural" de lo femenino se expresa en la voluntad incondicional que hace brotar de sí una potencia extraordinaria para detener el avance del mal.

5. El recurso del presente como temporalidad absoluta. A pesar de los saltos en el tiempo, se trabaja para un eterno presente sin nostalgia y sin demasiada esperanza; la fragilidad de las certezas y logros humanos se goza en el instante, como posesión efímera.

Con base en las consideraciones realizadas, concluimos que el relato de ciencia ficción fundado por Terminator no tiene su núcleo en la literatura científica, sino en la mítica; distinguimos entre el paisaje y la esencia del relato para señalar que los elementos de base científica se manifiestan en su superficie, pero su núcleo inherente es mítico: lo que cambia el mundo y los paradigmas no es la tecnología avanzada, sino la fuerza cósmica de la vida (Bachelard 150).

La estructura arquetipal de la versión de Terminator se sostiene primeramente en el modelo canónico de contrarios que, aunque adopta fisonomías diversas, se aúna siendo muestra de energías complementarias: amormuerte, paz-guerra, razón-violencia. Ese conjunto de fuerzas se corporiza en la personificación de la madre, ejemplo por antonomasia de pasión-agresión ordenada a la defensa de la vida. Los modelos de madre analizados tienen amplia justificación de motivos para transitar la ambigüedad de su carácter y hacer el movimiento de la paz a la guerra y de vuelta a la paz. El dilema ético de cualquier experiencia de tiempos y civilizaciones alternativos recae en el mismo fondo del corazón humano.

La eficacia del arquetipo mítico queda resignificada en el texto fílmico: el destino que se identifica con lo femenino solo puede ser rediseñado por un movimiento de la voluntad femenina, esto es, unificar el dolor en compasión y albergar al otro que sufre, sin tener culpa alguna.

\section{Obras citadas}

Baudrillard, Jean. The System of Objects. Londres: Verso, 1996. Impreso.

Bachelard, Gaston. La poética de la ensoñación. México: FCE, 1982. Impreso.

Becker, Daniel. "Desiring Fakes. AI, Avatars, and the Body of Fake Information in Digital Art". Faking, Forging, Counterfeiting. Discredited Practices at the Margins of Mimesis, editado por Daniel Becker, Annalisa Fischer y Yola Schmitz. Bielefeld: Transcript Verlag, 2018, pp. 199-222. Impreso. <https://doi.org/10.14361/9783839437629-013>. Accedido 1 dic. 2019.

Cantarella, Eva. La calamidad ambigua. Condición e imagen de la mujer en la antigüedad griega y romana. Madrid: Ediciones Clásicas, 1991. Impreso.

Conacher, Desmond J. Euripidean Drama. Myth, Theme and Structure. Toronto: University of Toronto Press, 1967. Impreso.

Croally, N. T. Euripidean Polemic: the Trojan Women and the Function of Tragedy. Cambridge: Cambridge University Press, 1994. Impreso.

Durand, Gilbert. Ciencia del hombre y tradición. El nuevo espíritu antropológico. Barcelona: Paidós Orientalia, 1999. Impreso.

---. Mitos y sociedades. Introducción a la mitodología. Buenos Aires: Biblos, 2003. Impreso.

---. De la mitocrítica al mitoanálisis. Barcelona: Anthropos, 2013. Impreso.

Easterling, Patricia Elizabeth. "Form and Performance". The Cambridge Companion to Greek Tragedy, editado por P. E. Easterling. Cambridge: Cambridge University Press, 1997, pp. 151-177. Impreso.

Eco, Umberto. "Science Fiction and the Art of Conjecture". Times Literary Supplement, no. 4257, 2 nov. 1984, pp. 12571258. Página web. <http://tinyurl.gale.com/tinyurl/C9Y8y8>. Accedido 1 dic. 2019.

Eurípides. Euripidis Fabulae, vol. 2, editado por Gilbert Murray. Oxford: Clarendon Press, 1913. Impreso.

Eurípides. Tragedias II, Las troyanas, introducción de Carlos García Gual, traducción de Eduardo Costa Méndez. Madrid: Gredos, 1995. Impreso.

García Gual, Carlos. "Sobre Las troyanas de Eurípides”. Mediterráneo: memoria y utopía, editado y coordinado por José Monleón, Madrid: Fundación Instituto Internacional del Teatro en el Mediterráneo/Murcia: Universidad de Murcia, 2011, pp. 281-292. Impreso.

Genette, Gérard. Palimpsestes. La littérature au second degré. Paris, Éditions du Seuil, 1982.

Grimal, Pierre. Diccionario de mitología griega y romana. Barcelona: Paidós, 1989. Impreso. 
Grube, George Maximilian Antony. The Drama of Euripides. Londres: Methuen, 1941. Impreso.

Hajdu, Péter. "The Ethical Discourse of Tragedy and (Pseudo-)Historiography”. Forum for World Literature Studies, vol. 8, no. 1, 2016, pp. 19-27 Página web. <http://real.mtak.hu/34818/1/DictysEnlish.pdf>. Accedido 1 dic. 2019.

Haraway, Donna J. Ciencia, cyborgs y mujeres. La reinvención de la naturaleza. Madrid: Cátedra, 1995. Impreso.

Jaeger, Werner. La teología de los primeros filósofos griegos. México: FCE, 2013. Impreso.

Jenkins, Henry. Convergence Culture: Where Old and New Media Collide. New York: New York University Press, 2006. Impreso.

Jünger, Friedrich. Los mitos griegos. Barcelona: Herder, 2006. Impreso.

Kerényi, Karl. Los dioses de los griegos. Caracas: Monte Ávila, 1997. Impreso.

Kirk, Geoffrey Stephen. Myth. Its meaning and functions in ancient and other cultures. Londres: Cambridge University Press, 1970. Impreso.

Lefkowitz, Mary R. Women in Greek Myth. Baltimore: Johns Hopkins University Press, 1986. Impreso.

Lesky, Albin. Historia de la literatura griega. Madrid: Gredos, 1976. Impreso.

Meltzer, Gary S. Euripides and the Poetics of Nostalgia. Cambridge: Cambridge University Press, 2006. Impreso.

Pavel, Thomas G. Fictional Worlds. Cambridge: Harvard University Press, 1986. Impreso.

Reale, Giovanni. Eros, demonio mediador. El juego de las máscaras en el Banquete de Platón. Barcelona: Herder, 2004. Impreso.

Romilly, Jacqueline de. La Grecia antigua contra la violencia. Madrid: Gredos, 2010. Impreso.

---. La tragedia griega. Madrid: Gredos, 2011. Impreso.

Shippey, Tom. Hard Reading. Learning from Science Fiction. Liverpool: Liverpool University Press. Impreso.

Schmeink, Lars. Biopunk Dystopias: Genetic Engineering, Society and Science Fiction. Liverpool: Liverpool University Press, 2016. Impreso.

Scodel, Ruth. "The Captive's Dilemma: Sexual Acquiescence in Euripides Hecuba and Troades". Harvard Studies in Classical Philology, 98, 1998, pp. 137-154. Página web. <www.jstor.org/stable/311340>. Accedido 1 dic. 2019.

Terminator: Dark Fate. Dirigida por Tim Miller, actuaciones de Linda Hamilton, Arnold Schwarzenegger, Mackenzie Davis y Natalia Reyes. Skydance Productions, Paramount Pictures, $20^{\text {th }}$ Century Fox y Tencent Pictures, 2019.

Vela Tejada, José. "Warfare, History and Literature in the Archaic and Classical Periods: the Development of Greek Military Treatises”. Historia: Zeitschrift Für Alte Geschichte, vol. 53, no. 2, 2004, pp. 129-146. Página web. <www. jstor.org/stable/4436720>. Accedido 1 dic. 2019.

Vernant, Jean-Pierre. La muerte en los ojos. Figuras del Otro en la antigua Grecia. Barcelona: Gedisa, 1986. Impreso.

Versnel, H. S. "The Gods: Divine Justice or Divine Arbitrariness?". Coping With the Gods: Wayward Readings in Greek Theology. Boston: Brill, 2011, pp. 151-237. Página web. <https://www.jstor.org/stable/10.1163/j.ctt1w76x2s.6>. Accedido 1 dic. 2019.

Vidal Naquet, Pierre. "L'honneur perdu et retrouvé d'Euripide", transcripción de la conferencia dada en la Academia del Sur, Buenos Aires, abril 1997. Impreso.

Volli, Ugo. "Gli universi paralleli della semiotica e della fantascienza". La fantascienza e la critica. Atti del Convegno internazionale di Palermo, editado por Luigi Russo. Milán: Feltrinelli, 1980, pp. 113-124. Impreso. 